\title{
CONSTRUCCIÓN DE UN CUESTIONARIO PARA MEDIR EL EMPRENDIMIENTO SOCIAL EN EDUCACIÓN FÍSICA
} THE CONSTRUCTION OF A QUESTIONNAIRE TO MEASURE SOCIAL ENTREPRENEURSHIP IN PHYSICAL EDUCATION CONSTRUÇÃO DE UM QUESTIONÁRIO PARA MEDIR O EMPREENDEDORISMO
SOCIAL EM EDUCAÇÃO FÍSICA Carlos CAPELLA PERIS, Jesús GIL GÓMEZ, Manuel MARTí PUIG \& Paola RUIZ-BERNARDO

Universidad Jaume I de Castellón

PALABRAS CLAVE: emprendimiento social aprendizaje-servicio educación física diseño de instrumentos

KEYWORDS

Social entrepreneurship service-learning physical education instrument design
RESUMEN: El presente artículo tiene por objetivo diseñar y validar un instrumento para medir el emprendimiento social sobre un colectivo de estudiantes universitarios participantes en programas de Aprendizaje-Servicio dentro del ámbito de la Educación Física. En primer lugar se realizó una revisión bibliográfica para determinar los rasgos característicos que definen al emprendedor social, para posteriormente elaborar un cuestionario inicial que valorara dichos rasgos. Seguidamente realizamos una revisión lógica, sometiendo dicho cuestionario al juicio de diversos expertos. Tras un exhaustivo proceso de filtrado, definimos el cuestionario piloto con el que realizamos una revisión empírica, aplicando el cuestionario sobre una muestra de 188 sujetos. Los resultados de la revisión lógica pusieron de manifiesto la calidad, relevancia y comprensión de los ítems seleccionados, descartando tan solo 2 de los 19 rasgos característicos del emprendedor social propuestos. Los resultados de la revisión empírica mostraron unos registros positivos, destacando una media total de 3,82 puntos sobre un máximo de 5. La validez y fiabilidad del cuestionario final quedó patente al obtener un registro de 0,809 en el Alfa de Cronbach, lo que sugiere la solidez interna del cuestionario. En cuanto al análisis factorial, los ítems se agruparon en tres grandes categorías, cuestión que, pese a no coincidir plenamente con nuestro planteamiento inicial, no variaba en exceso. Así pues, concluimos que la herramienta elaborada cumple nuestro objetivo inicial, siendo válida para medir el emprendimiento social. Su utilidad se fundamenta en la importancia de fomentar dicha competencia desde cualquier ámbito, especialmente desde el educativo.

ABSTRACT: This article aims to design and validate an instrument that measures the social entrepreneurship of a group of university students participating in service-learning programmes in the field of Physical Education. Firstly, a literature review was carried out to determine the characteristics that define the social entrepreneur, to latterly develop an initial questionnaire that assessed these traits. After that, a logical review was undertaken, submitting the aforesaid questionnaire to various experts. Following a thorough screening process, the pilot questionnaire on which the empirical review was carried was defined and the questionnaire was applied amongst a sample of 188 subjects. The results of the logical review highlighted the quality, relevance and understanding of the selected items, with only 


\begin{tabular}{|c|c|}
\hline & $\begin{array}{l}2 \text { of the } 19 \text { characteristics of social entrepreneurship proposed being eventually discarded. } \\
\text { The results of the empirical review gave a positive record, highlighting a total average of } \\
3.82 \text { points out of a possible } 5 \text {. The validity and reliability of the questionnaire was evident } \\
\text { as it obtained a score of } 0.809 \text { on Cronbach's alpha, which suggest the inner strength of the } \\
\text { questionnaire. In regard to factor analysis, the items were grouped into three broad cate- } \\
\text { gories, an issue which despite not coinciding fully with the initial approach, did not vary gre- } \\
\text { atly. Thus, we conclude that the elaborated tool fulfilled its initial objective, and was still } \\
\text { valid to measure social entrepreneurship. Its usefulness is based on the importance of pro- } \\
\text { moting this competency within any field, especially in the educational domain. }\end{array}$ \\
\hline $\begin{array}{l}\text { PALAVRAS-CHAVE: } \\
\text { empreendedorismo } \\
\text { social } \\
\text { serviço-aprendizagem } \\
\text { educação física } \\
\text { desenho do instrumento }\end{array}$ & $\begin{array}{l}\text { RESUMO: Este artigo tem como objetivo construir e validar um instrumento para medir o } \\
\text { empreendedorismo social em um grupo de estudantes universitários que participam em } \\
\text { programas de serviço-aprendizagem no âmbito da Educação Física. Primeiro, uma revisão } \\
\text { bibliográfica foi realizada para determinar as características que definem o empreendedor } \\
\text { social, para desenvolver um questionário inicial que avaliou essas características. Em se- } \\
\text { guida, realizamos uma revisão lógica, apresentando o questionário para análise de diversos } \\
\text { especialistas. Depois de um processo de triagem minuciosa, definimos o questionário-pi- } \\
\text { loto com o qual realizamos uma análise empírica, aplicando o questionário em uma amos- } \\
\text { tra de } 188 \text { indivíduos. Os resultados da avaliação lógica destacaram a qualidade, relevância } \\
\text { e compreensão dos itens selecionados, descartando apenas } 2 \text { das } 19 \text { características de em- } \\
\text { preendedorismo social propostos. Os resultados da análise empírica mostraram alguns re- } \\
\text { gistros positivos, com destaque para uma média total de } 3,82 \text { pontos, de um máximo de } 5 \text {. } \\
\text { A validade e confiabilidade do questionário final foi evidente ao obter um recorde de o,8o9 } \\
\text { em alfa de Cronbach, sugerindo a força interna do questionário. Quanto à análise fatorial, } \\
\text { os itens foram agrupados em três grandes categorias, uma questão que, apesar de não con- } \\
\text { cordar totalmente com a nossa abordagem inicial não variaba empresas excesso. Podemos } \\
\text { concluir que a ferramenta elaborada cumpre com o nosso objetivo inicial, sendi valida para } \\
\text { medir o empreendedorismo social. Sua utilidade é baseada na importância de promover } \\
\text { essa concorrência em qualquer campo, especialmente no da educação. }\end{array}$ \\
\hline
\end{tabular}

\section{Introducción}

El fomento del emprendimiento parece ser una de las recetas que diferentes estamentos de la sociedad contemporánea proponen como respuesta a la actual situación de crisis. Esta se ha manifestado con virulencia en el ámbito económico, teniendo una traslación directa al ámbito social, lo que ha provocado un empobrecimiento global de nuestra comunidad.

El fomento del emprendimiento puede ser una opción más para superar las crisis económica y social, generadas ambas por una falta evidente de valores democráticos. Como veremos a continuación, el emprendimiento, en sus versiones económica y social, tiene gran cantidad de elementos en común. No obstante, queremos resaltar que la diferencia fundamental entre estos dos tipos de emprendimiento radica en el objetivo o enfoque que los motiva, siendo el objetivo básico del emprendimiento social el desarrollo y mejora de la sociedad. Así pues, nuestro trabajo se centra en la vertiente social del mismo y, más concretamente, en la creación y validación de un instrumento de medida para valorarlo, generado a partir de la aplicación de la metodología del Aprendizaje-Servicio (en adelante APS) en el contexto docente universitario. En este sentido, consideramos que el mundo educativo es un buen vivero donde comenzar a desarrollar el emprendimiento social en nuestra sociedad. La innovación docente a través del uso de me- todologías activas y experienciales, propone un cambio sustancial en los roles tradicionales dentro del proceso de enseñanza/aprendizaje, propiciando un protagonismo del alumnado que da opción al desarrollo de competencias personales además de las básicas? Vinculada a esta propuesta, destacamos la metodología del APS, pues cuenta con un doble objetivo (Gil, 2012): pretende el aprendizaje de contenidos académicos a la vez que se presta un servicio a la sociedad atendiendo alguna necesidad real no cubierta. De acuerdo con esta concepción, el APS genera una serie de situaciones en el proceso de enseñanza/aprendizaje en las que se ponen en juego valores y actitudes prosociales coincidentes con los rasgos que debe tener un o una emprendedor/a social. Es aquí donde aparece el puente que conecta la educación con el emprendimiento social, desde la promoción de la participación, implicación y compromiso de los estudiantes en y con su comunidad local, como acertadamente defiende Cieza (2010). Este razonamiento, convenientemente ampliado en apartados posteriores, es el que justifica la elección de la muestra de esta investigación para la validación del cuestionario sobre emprendimiento social.

\section{Justificación}

El interés por el emprendimiento no es una cuestión novedosa. Orrego (2009) señala que se viene evidenciando tanto en el ambiente académico como en 
el empresarial a lo largo de las últimas dos décadas en instituciones públicas, privadas y sociales. Pese a ello, Europa es una de las zonas menos emprendedoras del mundo. En España únicamente el 7,3\% de la población comprendida entre 18 y 65 años participa en actividades empresariales de nueva creación (De la Vega, Corduras, Justo \& González, 2006). Además, esta misma publicación señala que el porcentaje de jóvenes emprendedores menores de 25 años no supera el 10\%. Este dato indica que existe un camino por recorrer pleno de posibilidades, en el que el campo de la educación puede adquirir un protagonismo importante siempre y cuando no dirijamos los esfuerzos formativos únicamente a la dimensión económica del término. Más bien somos de la opinión que potenciar aspectos sociales del emprendimiento se alinea adecuadamente con la filosofía emanada por la legislación educativa.

Según la Real Academia Española (2012), emprender supone "acometer y comenzar una obra, un negocio, un empeño, especialmente si encierran dificultad o peligro". Para Lanzas, A., Lanzas, V. y Castaño (2006) el emprendimiento hace referencia a la capacidad de generar ideas, identificar oportunidades y definir escenarios adecuados para convertirlas en realidad, teniendo una relación directa con la capacidad de adaptarse a diferentes equipos de trabajo, además de ser capaz de generar nuevos equipos y liderarlos. Como características complementarias, Aliaga y Schalk (2010) y González y Zúñiga (2011) añaden la autonomía y la capacidad de decisión y de organización de recursos. De la misma forma, emprender está relacionado con la capacidad de análisis de factores exógenos (económicos, sociales, ambientales y políticos) así como de endógenos (capacidad de disponer de personas así como de recursos físicos y financieros) de acuerdo con Valls, Villa, Martínez y Hernando (2009). Esta aproximación conceptual nos muestra que ser emprendedor es una cualidad poliédrica, que supone la integración de muchas capacidades personales. Estas características serían comunes a las dos versiones de emprendimiento expuestas, económica y social. En nuestro trabajo nos centramos en el emprendimiento social y en las posibilidades que el ámbito educativo ofrece para su desarrollo. Por ello, pasamos a profundizar sobre sus características.

Como nos señala Enciso (2010), el emprendimiento social hace referencia a las iniciativas de individuos que quieren sacar adelante proyectos de naturaleza solidaria y sin ánimo de lucro. Así pues, a diferencia de otras formas de emprendimiento que se centran básicamente en crear valor financiero, el emprendimiento social pretende generar un valor de carácter social dirigido a cubrir una necesidad social existente (Auerswald, 2009), por lo que se orienta hacia la transformación social (Valls, Villa, Martínez \& Hernando, 2009). Debemos recalcar que este emprendimiento social no se refiere a actividades caritativas, pues aunque su objetivo fundamental no sea obtener beneficios económicos puede ser igualmente rentable en otros términos. Para entender mejor esta posición, podemos remitirnos a la matriz del emprendimiento social descrita por Massetti (2008), en la que lo ubica en un punto intermedio entre la misión social, las actividades sin fines lucrativos, la rentabilidad y el mercado financiero.

Según Zahra, Filatotchev y Wrigth (2009), el emprendimiento social abarca las actividades y procesos que se llevan a cabo para descubrir, definir y explotar oportunidades con el objetivo de aumentar la riqueza social, creando nuevas empresas o dirigiendo las organizaciones existentes de una manera innovadora. La empresa social, principal forma de organización de este modelo de emprendimiento, emerge a lo largo del siglo XXI con el objetivo de resolver problemas sociales de una manera sostenible (Palacios, 2010). Otros autores también lo entienden como un proceso de construcción, evaluación y persecución de oportunidades para un cambio social (Roberts \& Woods, 2005).

La bibliografía muestra el emprendimiento social como una fuente de creación de oportunidades en el futuro próximo (Short, Moss \& Lumpkin, 2009) tanto para el progreso económico como social, desde la concepción de que su desarrollo conduce a cambios significativos en la vida social, política y en el contexto económico (Alvord, Brown \& Letts, 2004). La dinamización de este capital social puede conducir a la construcción de un modelo diferente de sociedad, planteando una alternativa de crecimiento económico basado en fundamentos muy diferentes a los convencionales. En este sentido, existen ejemplos de éxito que pueden guiar la acción futura (Spear, 2006). Ahondando en este tema, podemos decir que su extensión es aún una cuestión pendiente, de la misma forma que la investigación sobre el emprendimiento social (Hoogendoorn, Pennings \& Thurik, 2010)

A efectos de sistematizar la investigación y poder desarrollar herramientas adecuadas que midan la capacidad de emprender socialmente, como es el objeto de esta investigación, es necesario analizar conductas, valores o actitudes, rasgos en definitiva, que aparezcan en las personas sobre las que se ha trabajado en este sentido. Varios autores determinan que existe relación entre los rasgos de la personalidad emprendedora y el comportamiento emprendedor (Chell, Haworth, \& Brearley, 1991; Rauch \& Frese, 2000), evidenciando su validez predictiva (Collins, Hanges \& Locke, 2004; Rauch \& Frese, 2007; Stewart \& Roth, 2001 y 2004; Zhao \& Seibert, 2006). Esta circunstancia impulsa a profundizar en los rasgos de la persona emprendedora social para poder elaborar un instrumento adecuado que los detecte y grade adecuadamente.

Los Ministerios de Educación y Ciencia y de Industria, Comercio y Turismo (2003) describen los 
nueve valores indispensables del espíritu emprendedor. Estos se dividen en personales, entre los que encontramos creatividad, autonomía, confianza en uno mismo, tenacidad, sentido de la responsabilidad y capacidad para asumir riesgos; y sociales, donde se ubican el liderazgo, el espíritu de equipo y la solidaridad. De Pablo, Santos y Bueno (2004) completan esta conceptualización revisando los rasgos más asociados a la personalidad emprendedora, presentando un total de 43. Entre ellos destacamos: necesidad y/o reconocimiento de logro, aceptación de riesgos moderados, creatividad / imaginación / innovación, liderazgo, orientado hacia la oportunidad, capacidad de conseguir recursos, toma de iniciativa / nuevos retos, autoconfianza / control interno, perseverancia / compromiso total, versatilidad / flexibilidad, orientación hacia metas específicas, planificación, seguimiento sistemático, redes de contacto, responsabilidad personal, planifican con límites de tiempo y necesidad de aprobación. Podemos comprobar que, a pesar de definir la personalidad emprendedora en general, siempre aparecen rasgos ligados a la versión más social de este concepto. Es decir, las propias definiciones de la personalidad emprendedora ya incluyen una parte (aunque minoritaria) de características sociales.

Profundizar en esta temática nos acerca específicamente a la personalidad emprendedora social. Para Weerawardena y Sullivan (2006) existen siete dimensiones que la definen: interacción con el entorno, capacidad de innovación, prosocialidad, gestión del riesgo, sostenibilidad, misión social, y búsqueda y reconocimiento de oportunidades. En una línea similar, Bacq y Janssen (2011), Choi y Majumdar (2014) y Haugh (2005) consideran que la creación de valor social, la innovación social, la organización del emprendimiento social, la orientación de mercado y la capacidad de encontrar soluciones innovadoras a los problemas sociales de su comunidad son sus características principales.

Teniendo en cuenta todas las cualidades descritas por los diferentes autores, a continuación sintetizamos los 19 rasgos característicos que, a priori, definen a un emprendedor social y que deben entrar a formar parte de la herramienta de medida que se va a crear: confianza, responsabilidad, liderazgo, organización, motivación al logro, capacidad para asumir riesgos, estar integrado en redes sociales con acceso a información y conocimiento, tolerancia, cooperación y ayuda, coherencia y compromiso, conciencia social, convivencia y respeto por el bien público, creatividad, iniciativa, capacidad para identificar oportunidades, capacidad para generar ideas, capacidad de cambio, capacidad para aprender y evolucionar, y tolerancia al fracaso.

Una vez definidos estos aspectos característicos, realizamos una búsqueda bibliográfica de cuestionarios que los midieran. Entre los cuestionarios encontrados, destacamos los siguientes: cuestionario para medir la capacidad emprendedora (Kafati, 2012), Test de perfil emprendedor (Centros Europeos de Empresas Innovadoras, 2012), Entrepreneurial inclinations of prospective teachers (Akhtar, Keith \& Riaz, 2009) y Entrepreneur attitude orientarion (Huefner, Hunt \& Robinson, 1996). Finalmente, para resaltar la importancia del componente social del emprendimiento, tuvimos en consideración el test AECS: actitudes y estrategias cognitivas sociales (Moraleda, González \& García-Gallo, 2004) en la parte dedicada a la prosocialidad, y el cuestionario de actitudes hacia la responsabilidad social (Alonso, 2004). Entre todos estos tests, seleccionamos aquellos ítems que hacían referencia a alguno de los 19 rasgos característicos del emprendedor social descritos anteriormente, formando así el cuestionario inicial sobre el que realizaríamos el proceso de validación.

La elección del ámbito educativo para realizar la validación no es casual. El enfoque competencial es la línea predominante en la actual legislación educativa, proponiendo un cambio metodológico en los procesos de enseñanza/aprendizaje. Se trata de superar el saber para incidir en el saber hacer y saber ser o estar. Este cambio supone optar por el uso de metodologías activas y experienciales en el que el alumnado ponga en juego capacidades para alcanzar las competencias, muchas de ellas caracterizadas por la adquisición de valores y actitudes necesarias para la vida. Estos preceptos son perfectamente cumplidos por el APS que, con un fuerte componente social, es una metodología adecuada para su desarrollo (Langstraat \& Bowdon, 2011; Manes, Hatt \& Wideman, 2013). Este es el punto común entre la adquisición de actitudes y valores a través del proceso de enseñanza/aprendizaje mediante APS y la mejora de aquellos que forman parte del proceso de emprendimiento social.

\section{Objetivo}

Visto el creciente interés sobre el emprendimiento social y los posibles beneficios que su influencia puede aportar al área educativa, el objetivo específico del presente trabajo es diseñar y validar un instrumento para medir el emprendimiento social sobre un colectivo de estudiantes universitarios, del grado de Maestro/a en Educación Infantil de la Universitat Jaume I de Castellón, participantes en programas de Aprendizaje-Servicio dentro del ámbito de la Educación Física.

\section{Metodología}

Para realizar el proceso de diseño y validación del instrumento que midiera la competencia de emprendimiento social se realizaron dos acciones de valoración secuenciadas en dos fases. Una revisión lógica, para seleccionar los ítems del cuestionario pi- 
loto, y una revisión empírica, para analizar la aplicación del cuestionario y así depurar y consolidar el cuestionario final.

Fase I: Revisión lógica. Esta fase se realizó en Marzo de 2013.

Diseño: el cuestionario fue objeto de una validación de constructo mediante juicio de expertos (Escobar-Pérez \& Cuervo-Martínez, 2008; González, Sánchez \& Jornet, 2011), donde éstos valoraron la calidad, relevancia, comprensión y dimensión a la que debía asociarse cada ítem.

Instrumento: el formulario de valoración que se utilizó para la consulta a los jueces constaba de una primera parte que incluía las dimensiones y los aspectos a evaluar y los criterios de evaluación (tabla 1); y de una segunda parte que incluía el cuestionario inicial que constaba de 96 ítems los cuales estaban repartidos en 19 dimensiones (anexo 1).

Participantes: para que el equipo de expertos valorara adecuadamente el cuestionario inicial, al seleccionarlos tuvimos en cuenta qué queríamos medir y dónde lo íbamos a aplicar tal como sugieren Escobar-Pérez y Cuervo-Martínez (2008). Por ello, ya que el cuestionario pretendía medir el perfil emprendedor social, el primer grupo de expertos estaba formado por tres personas, un experto en emprendimiento social con numerosas publicaciones $y$ actividades al respecto, un miembro de diversas asociaciones de carácter social habituado al trato humano y solidario, y un miembro de un equipo de formación para la inclusión y la participación social. En cuanto al segundo grupo, dado que la aplicación del cuestionario se iba a llevar a cabo en el entorno educativo universitario, lo formaron tres docentes universitarios con experiencia en APS, formación e innovación docente, y emprendimiento social.

Fase II: Revisión empírica. Esta fase se realizó en Junio de 2013.

Diseño: En esta segunda fase se sigue un diseño de tipo descriptivo cuyo objeto es corroborar el funcionamiento de los ítems y del cuestionario piloto para medir la competencia de emprendimiento social.

Instrumento: el cuestionario piloto estaba formado por 30 ítems que se distribuía en 17 dimensiones (anexo 2). Se utilizó una escala de 5 puntos que varían desde el "muy en desacuerdo" hasta el "muy de acuerdo".
Tabla 1: Criterios para la valoración de los ítems

\begin{tabular}{|l|l|}
\hline Calidad & $\begin{array}{l}\text { ¿Considera que la formulación del ítem es } \\
\text { de calidad?: } \\
\text { 1. Mucha } \\
\text { 2. Regular } \\
\text { 3. Poca }\end{array}$ \\
\hline Relevancia & $\begin{array}{l}\text { cEl ítem mide un aspecto relevante sobre } \\
\text { el concepto de emprendimiento social? }\end{array}$ \\
\hline 1. Muy relevante \\
2. Relevante \\
3. Nada relevante
\end{tabular}

Participantes: para valorar adecuadamente la muestra debemos tener en consideración, como ya hemos comentado, que la creación del presente cuestionario es el paso inicial de una investigación que pretende estudiar los efectos del Aprendizaje-Servicio sobre el alumnado universitario en cuanto al emprendimiento social durante la realización de activi- 
dades pertenecientes al ámbito de la Educación Física. Por lo tanto, la muestra debía estar compuesta por alumnos/as de la universidad que hubieran realizado programas de Aprendizaje-Servicio en el campo de la Educación Física, motivo por el cual esta fase se realizó tres meses después de la anterior. Teniendo en cuenta estas premisas, la muestra estaba formada por un colectivo de 188 sujetos (alumnos y alumnas universitarios) pertenecientes al grado de Magisterio Infantil, que habían participado en programas de Aprendizaje-Servicio relacionados con la Educación Física en sus primeros años de formación. Por tanto el muestreo ha sido de tipo fortuito o accidental.

\section{Resultados}

\section{Resultados de la revisión lógica}

A continuación presentamos los resultados del análisis de los datos proporcionados por el equipo de expertos, utilizando el programa SPSS Statistics 20 , respecto a la valoración de los ítems del cuestionario piloto. Como ya hemos indicado, los aspectos valorados fueron calidad, relevancia y comprensión; el aspecto sobre la dimensión a la que debía asociarse cada ítem se ha valorado de un modo diferente por tratarse de datos nominales.

Para medir el nivel de acuerdo entre los jueces utilizamos el Coeficiente de Concordancia de Kendall (W), pues este coeficiente muestra, el acuerdo o, mejor dicho, la concordancia entre los jueces en función del criterio consultado, en relación con todas las valoraciones de todos los ítems del instrumento. Seguidamente presentamos los resultados obtenidos en las categorías de calidad, relevancia y comprensión, presentándolos en conjunto y por grupos de jueces, ver tabla 2.

El resultado de $\mathrm{W}$ de Kendall para la valoración de la calidad determina que existe acuerdo entre jueces y que éste es débil pero significativo en todos los casos. En cuanto a la valoración de la relevancia los datos indican que existe acuerdo entre jueces, siendo significativo en todos los casos, débil para el conjunto de todos los jueces y moderado en los grupos por separado. Respecto a la comprensión, la W de Kendall muestra que existe acuerdo entre jueces, de nuevo significativo en todos los casos, débil para el conjunto de todos los jueces y en los jueces de las asociaciones, y moderado en el grupo de jueces universitarios. Como también se observa en la tabla 2 , son más concordantes los grupos de expertos entre sí que por separado. Esto podemos atribuirlo a la misma dualidad que le da sentido a la formación de estos dos grupos, es decir, al tratar de conjugar la formación y la experiencia en este tema. Dicha situación podría abrir nuevas cuestiones a debate tal como postulan Summers, Williamson y Read (2004).

\begin{tabular}{|l|c|c|c|}
\hline \multicolumn{4}{|c|}{$\begin{array}{r}\text { Tabla 2: Coeficientes de Concordancia de Kendall (W) } \\
\text { para la valoración de la calidad, relevancia y } \\
\text { comprensión por grupos de jueces }\end{array}$} \\
\hline Criterio & $\begin{array}{c}\text { Todos los } \\
\text { jueces W de } \\
\text { Kendall }\end{array}$ & $\begin{array}{c}\text { Jueces } \\
\text { Universita- } \\
\text { rios W de } \\
\text { Kendall }\end{array}$ & $\begin{array}{c}\text { Jueces de } \\
\text { las Asocia- } \\
\text { cionesW } \\
\text { de Kendall }\end{array}$ \\
\hline Calidad &, 233 &, 391 &, 376 \\
\hline Relevancia &, 313 &, 446 &, 444 \\
\hline Comprensión &, 219 &, 408 &, 336 \\
\hline
\end{tabular}

Tras analizar los datos aportados por el juicio de expertos se estableció un procedimiento para el filtrado de los ítems más apropiados en función de tres criterios. El primer criterio requería que la media de resultados debía ser menor o igual que 1,5 descartando todos los ítems con una media mayor (eso se debe a que la escala priorizaba el 1 como el más importante y el 3 como el menos importante), lo que nos aseguraría que los ítems seleccionados tuvieran una elevada puntuación en los tres primeros criterios valorados. El segundo criterio hacía referencia al coeficiente de variación, descartando todos aquellos ítems con registros superiores a un $37 \%$ (en este criterio se considera que a partir de un 35\% la distribución es heterogénea), lo que garantizaría una distribución homogénea de los ítems seleccionados. Por último, el criterio utilizado para filtrar los ítems en cuanto a la dimensión asociada sería la moda. Así pues, se descartaron aquellos ítems que no tuvieran al menos un 50\% de acuerdo en cuanto a la dimensión asociada a la que hacían referencia, por lo que para seleccionar un ítem al menos tres de los seis jueces tenían que asociarlo a la misma dimensión.

Tras el filtrado descrito pasamos de un cuestionario inicial de 96 ítems que representaba los 19 rasgos característicos del emprendedor social, distribuidos en tres grandes categorías, a un cuestionario piloto con tan sólo 30 ítems. Pese a la notable reducción de ítems, tan sólo se descartaron 2 de los rasgos característicos planteados inicialmente, ya que ninguno de los ítems que hacían referencia a dichos rasgos superaron los criterios de selección anteriormente descritos. El primer rasgo característico descartado fue la organización, perteneciente a la categoría de aspectos de carácter personal, mientras que el segundo fue la tolerancia, perteneciente a la categoría de aspectos de carácter social. Cabe destacar que la distribución de los 30 ítems seleccionados era muy equilibrada. 


\section{Resultados de la revisión empírica}

Una vez realizado el cuestionario piloto lo sometimos a una prueba empírica para observar el comportamiento de los ítems y del cuestionario en general.

En cuanto a los datos descriptivos obtenidos que se pueden observar en la tabla 3, nos gustaría destacar que el registro más bajo es una media 2,63 puntos (ítem 2) y el más alto 4,64 puntos (ítem 16), obteniendo una media total para toda la población de 3,82 puntos, como podemos ver en el gráfico 1, donde se presenta un histograma con la distribución de los sujetos según el grado de competencia alcanzado. Estos datos ponen de manifiesto los elevados registros obtenidos al pasar el cuestionario.

Gráfico 1: Histograma del paso de la prueba piloto

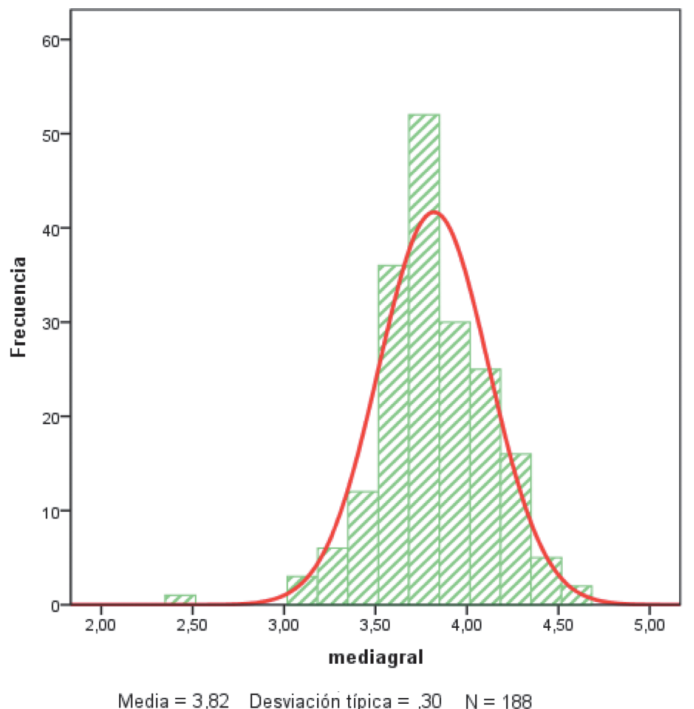

Posteriormente para observar la fiabilidad de la prueba se realizó un análisis general de la escala a través del Alfa de Cronbach y el resultado fue de 0,809 lo que nos sugiere la solidez interna del cuestionario. También se utilizó la misma prueba con cada uno de los ítems. Se observó que el Alfa de la escala en general no mejoraba significativamente si se eliminaba algún ítem. Así pues, se puede apreciar que todos los ítems son importantes para valorar la competencia de emprendimiento social y que el cuestionario creado permite medir dicha competencia, ver tabla 4.

También se realizó un análisis factorial, este análisis nos permite observar la estructura interna del cuestionario identificando las categorías en las que se agrupan los ítems. Los estudios que se realizaron previamente de la base de datos empíricos nos confirman que es posible este análisis en cuanto se cumplen las premisas básicas para su realización. A continuación se exponen los resultados de los es-

\begin{tabular}{|c|c|c|}
\hline \multicolumn{3}{|c|}{ Tabla 3: Estadísticos de los elementos } \\
\hline Ítems & Media & Desviación típica \\
\hline i1 & 3,40 & 917 \\
\hline i2 & 2,63 & ,986 \\
\hline i3 & 4,18 & ,708 \\
\hline i4 & 4,22 & ,606 \\
\hline i5 & 4,16 & ,760 \\
\hline i6 & 3,55 & 741 \\
\hline i7 & 3,66 & ,679 \\
\hline i8 & 3,93 & 697 \\
\hline i9 & 3,87 & ,666 \\
\hline i10 & 4,27 & ,634 \\
\hline $\mathrm{i} 11$ & 4,12 &, 768 \\
\hline $\mathrm{i} 12$ & 3,87 & ,986 \\
\hline$i 13$ & 3,22 & ,896 \\
\hline $\mathrm{i14}$ & 3,73 & 881 \\
\hline i15 & 4,35 & ,656 \\
\hline $\mathrm{i16}$ & 4,64 &, 572 \\
\hline i17 & 4,32 & ,626 \\
\hline ¡18 & 4,59 & 610, \\
\hline i19 & 3,69 & 740 \\
\hline i20 & 3,62 & 663, \\
\hline i21 & 3,72 & 603, \\
\hline $\mathrm{i} 22$ & 3,06 & 1,058 \\
\hline i23 & 2,77 & 1,177 \\
\hline i24 & 3,96 & ,636 \\
\hline $\mathrm{i} 25$ & 3,87 & ,752 \\
\hline i 26 & 3,52 & ,705 \\
\hline i27 & 3,50 &, 742 \\
\hline $\mathrm{i} 28$ & 3,77 & 905, \\
\hline $\mathrm{i} 29$ & 4,19 & ,581 \\
\hline i30 & 4,19 & 590, \\
\hline
\end{tabular}

tudios previos. Para la medida de adecuación muestral de KMO (Kaiser-Meyer-Olkin) es 0,754, dato que se considera positivo en tanto el valor puede oscilar entre 0 y 1 , y el registro de la prueba de esfericidad de Bartlett es $\mathrm{p}=0,000$, es decir que existen correlaciones significativas entre las variables para poder realizar un análisis factorial.

El análisis factorial se ha realizado utilizando el método de análisis de componentes principales, con rotación de normalización Oblimin con Kaiser, ya que esta tiene una función exploratoria. En la tabla 5 se puede observar la saturación de cada ítem en cada categoría. 


\begin{tabular}{|c|c|c|c|c|}
\hline \multicolumn{5}{|c|}{ Tabla 4: Estadísticos total-elemento } \\
\hline Ítems & $\begin{array}{c}\text { Media de la escala si se } \\
\text { elimina el elemento }\end{array}$ & $\begin{array}{l}\text { Varianza de la escala si se } \\
\text { elimina el elemento }\end{array}$ & $\begin{array}{c}\text { Correlación ele- } \\
\text { mento-total corregida }\end{array}$ & $\begin{array}{l}\text { Alfa de Cronbach si se eli- } \\
\text { mina el elemento }\end{array}$ \\
\hline i1 & 111,17 & 74,859 & ,330 & ,803 \\
\hline i2 & 111,95 & 75,462 &, 262 & ,807 \\
\hline i3 & 110,39 & 75,128 & ,432 & ,799 \\
\hline i4 & 110,35 & 76,625 & 371 & ,802 \\
\hline i5 & 110,41 & 76,863 & ,262 & ,806 \\
\hline i6 & 111,03 & 75,791 & ,356 & ,802 \\
\hline ¡7 & 110,91 & 74,838 & ,479 & ,798 \\
\hline i8 & 110,65 & 75,266 & ,428 & 800 \\
\hline i9 & 110,70 & 74,905 & ,484 & ,798 \\
\hline i10 & 110,30 & 75,421 & ,464 & ,799 \\
\hline$i 11$ & 110,45 & 75,789 & 341 & ,803 \\
\hline i12 & 110,71 & 77,096 & 165 & ,812 \\
\hline i13 & 111,36 & 76,295 & 245 & 807 \\
\hline i74 & 110,85 & 76,024 & ,269 & ,806 \\
\hline i15 & 110,23 & 75,193 & 466 & ,799 \\
\hline i16 & 109,93 & 77,840 & ,274 & ,805 \\
\hline i17 & 110,25 & 75,718 & 443 & 800 \\
\hline i18 & 109,99 & 76,888 & 343 & ,803 \\
\hline i19 & 110,89 & 75,287 & 397 & ,801 \\
\hline $\mathrm{i} 20$ & 110,95 & 76,313 & ,361 & ,802 \\
\hline i21 & 110,86 & 76,124 & ,422 & 801 \\
\hline $\mathrm{i} 22$ & 111,51 & 78,347 & , O78 & ,817 \\
\hline i23 & 111,80 & 80,277 & -,O35 & 826 \\
\hline i24 & 110,62 & 76,804 & ,334 & 803 \\
\hline $\mathrm{i} 25$ & 110,71 & 75,213 & ,395 & ,801 \\
\hline $\mathrm{i} 26$ & 111,05 & 76,254 & ,340 & 803 \\
\hline i27 & 111,07 & 75,438 & ,383 & 801 \\
\hline $\mathrm{i} 28$ & 110,80 & 75,175 & ,315 & 804 \\
\hline i29 & 110,38 & 76,548 & 398 & ,802 \\
\hline i3o & 110,38 & 75,906 & ,455 & ,800 \\
\hline
\end{tabular}




\begin{tabular}{|c|c|c|c|}
\hline \multicolumn{4}{|c|}{$\begin{array}{c}\text { Tabla 5: Análisis factorial de los resultados } \\
\text { de la prueba piloto }\end{array}$} \\
\hline \multirow[t]{2}{*}{ Ítem } & \multicolumn{3}{|c|}{ Componente } \\
\hline & 1 & 2 & 3 \\
\hline i7 & ,426 & , O79 &,- 064 \\
\hline i2 & 259, & 159, &,- 186 \\
\hline i3 & ,334 & -132 & -720 \\
\hline i4 & 245 &,$- \mathrm{O} 34$ & -635 \\
\hline i5 & ,247 & -167 &,- 363 \\
\hline i6 & ,224 & ,009 &,- 587 \\
\hline i7 & 212 & ,257 &,- 714 \\
\hline i8 & 183, & 200, & -,704 \\
\hline i9 & 194 & ,287 &,- 746 \\
\hline i10 & ,560 & ,017, &,- 426 \\
\hline in & ,496 &,- 083 &,- 232 \\
\hline i12 & 291 & 221 & 134 \\
\hline i13 & ,215 & 341, &,- 046 \\
\hline i74 & 298, & , 019 & -160 \\
\hline i15 & 653, &,- 081 &,- 252 \\
\hline $\mathrm{i} 16$ &, 568 &,- 358 & -147 \\
\hline i17 &, 578 & , ০০০ &,- 365 \\
\hline ¡18 & 638 &,- 179 &,- 167 \\
\hline i19 &, 524 & ,262 &,- 215 \\
\hline $\mathrm{i} 20$ & ,443 &, 548 & ,099 \\
\hline i21 & ,379 & ,537 &,- 206 \\
\hline i22 &,- 091 &, 508 & ,066 \\
\hline $\mathrm{i} 23$ & 140 & 270, & 130, \\
\hline i24 &, 563 & , O68 &,- 058 \\
\hline i 25 & ,519 & 127, &,- 182 \\
\hline i 26 & 164 & ,559 &,- 307 \\
\hline i27 & 178 & 631, &,- 321 \\
\hline i28 & , 165 & 443 &,- 347 \\
\hline i29 & ,560 & 189, & -201 \\
\hline i30 &, 534 & 213, &,- 258 \\
\hline
\end{tabular}

Respecto a la extracción de factores comunes, los ítems se agrupan en tres grandes categorías, algo que concuerda con nuestro planteamiento teórico inicial. Como se puede observar, en la tabla 6, la agrupación explica el 34 '9\% de la varianza acumulada. No obstante, las tres categorías en las que se agrupan los ítems no coinciden completamente con las planteadas de inicio. La nueva categoría 1 presenta una mezcla de las categorías 1 y 2 iniciales, la categoría 2 actual se asemeja mucho a la anterior categoría 3 y, finalmente, la nueva categoría 3 contiene tres de los rasgos ubicados inicialmente en la categoría 1. Teniendo en cuenta estas agrupaciones y los rasgos característicos representados en cada una de ellas, consideramos oportuno renombrar las categorías de la siguiente manera: categoría 1- rasgos personales y sociales del emprendedor social; categoría 2- rasgos innovadores del emprendedor social; y categoría 3- rasgos de ejecución del emprendedor social. Esta nueva clasificación no dista mucho de la propuesta inicial, por lo que consideramos que puede deberse a cuestiones meramente terminológicas o de interpretación de los rasgos característicos analizados. A continuación, mostramos la tabla 7 donde se expone la nueva organización de los ítems y, por consiguiente, de los 17 rasgos característicos definitivos que sugerimos definen al emprendedor social. 


\begin{tabular}{|c|c|c|c|c|c|c|c|}
\hline \multicolumn{8}{|c|}{ Tabla 6: Extracción de factores comunes tras el paso de la prueba piloto, varianza total explicada } \\
\hline \multirow{2}{*}{$\begin{array}{l}\text { Compo- } \\
\text { nente }\end{array}$} & \multicolumn{3}{|c|}{ Autovalores iniciales } & \multicolumn{3}{|c|}{$\begin{array}{l}\text { Sumas de las saturaciones al cua- } \\
\text { drado de la extracción }\end{array}$} & \multirow{2}{*}{$\begin{array}{c}\text { Suma de las saturaciones al } \\
\text { cuadrado de la rotación }\end{array}$} \\
\hline & Total & $\begin{array}{c}\% \\
\text { varianza }\end{array}$ & $\begin{array}{c}\% \\
\text { acumulado }\end{array}$ & Total & $\begin{array}{c}\% \\
\text { varianza }\end{array}$ & $\begin{array}{c}\% \\
\text { acumulado }\end{array}$ & \\
\hline 1 & 5,820 & 19,401 & 19,401 & 5,820 & 19,401 & 19,401 & 4,829 \\
\hline 2 & 2,545 & 8,485 & 27,886 & 2,545 & 8,485 & 27,886 & 2,604 \\
\hline 3 & 2,114 & 7,045 & 34,931 & 2,114 & 7,045 & 34,931 & 4,108 \\
\hline 4 & 1,836 & 6,119 & 41,050 & & & & \\
\hline 5 & 1,621 & 5,404 & 46,455 & & & & \\
\hline 6 & 1,491 & 4,969 & 51,424 & & & & \\
\hline 7 & 1,337 & 4,456 & 55,879 & & & & \\
\hline 8 & 1,207 & $4, \mathrm{O} 23$ & 59,902 & & & & \\
\hline 9 & 1,089 & 3,632 & 63,534 & & & & \\
\hline 10 & ,961 & 3,204 & 66,738 & & & & \\
\hline 11 & ,946 & 3,153 & 69,891 & & & & \\
\hline 12 & 873 & 2,910 & 72,801 & & & & \\
\hline 13 & ,762 & 2,541 & 75,343 & & & & \\
\hline 14 & ,741 & 2,471 & 77,814 & & & & \\
\hline 15 & ,662 & 2,208 & 80,022 & & & & \\
\hline 16 & ,652 & 2,174 & 82,196 & & & & \\
\hline 17 &, 544 & 1,815 & 84,010 & & & & \\
\hline 18 & ,527 & 1,758 & 85,768 & & & & \\
\hline 19 & , 490 & 1,632 & 87,401 & & & & \\
\hline 20 & , 473 & 1,577 & 88,977 & & & & \\
\hline 21 & ,453 & 1,509 & 90,487 & & & & \\
\hline 22 & ,440 & 1,467 & 91,954 & & & & \\
\hline 23 & ,388 & 1,293 & 93,247 & & & & \\
\hline 24 &, 367 & 1,224 & 94,470 & & & & \\
\hline 25 & ,335 & 1,118 & 95,588 & & & & \\
\hline 26 & ,307 & 1,024 & 96,613 & & & & \\
\hline 27 & ,298 & ,992 & 97,605 & & & & \\
\hline 28 & ,254 & 846 & 98,451 & & & & \\
\hline 29 & ,240 & ,802 & 99,253 & & & & \\
\hline 30 & ,224 & ,747 & 100,000 & & & & \\
\hline
\end{tabular}

[Carlos CAPELLA PERIS, Jesús GIL GÓMEZ, Manuel MARTí PUIG \& Paola RUIZ-BERNARDO] SIPS - PEDAGOGIA SOCIAL. REVISTA INTERUNIVERSITARIA [(2016) 28, 169-188] TERCERA ÉPOCA Copyright $\odot 2016$ SIPS. Licencia Creative Commons Attribution-Non Commercial (by-nc) Spain 3.0 
Tabla 7: Organización de los ítems del cuestionario y de los rasgos característicos que definen al emprendedor social en función de los resultados estadísticos

\begin{tabular}{|c|c|}
\hline Nombre de la categoría & Ítems incluidos en la categoría y rasgo característico al que hace referencia \\
\hline $\begin{array}{l}\text { Categoría } 1 \\
\text { Rasgos personales y } \\
\text { sociales del emprendedor } \\
\text { social. }\end{array}$ & $\begin{array}{l}1 \text { y } 2 \text { (liderazgo). } \\
10 \text { y } 1 \text { (responsabilidad). } \\
12 \text { (estar integrado en redes sociales con acceso a información y conocimiento). } \\
14 \text { y } 16 \text { (conciencia social). } \\
15 \text { (cooperación y ayuda). } \\
17 \text { (coherencia y compromiso). } \\
18 \text { (convivencia y respeto por el bien público). } \\
19 \text { (creatividad). } \\
24 \text { y } 25 \text { (capacidad de generar ideas). } \\
29 \text { (capacidad para aprender y evolucionar). } \\
30 \text { (tolerancia al fracaso). }\end{array}$ \\
\hline $\begin{array}{l}\text { Categoría } 2 \\
\text { Rasgos innovadores } \\
\text { del emprendedor social. }\end{array}$ & $\begin{array}{l}13 \text { (estar integrado en redes sociales con acceso a información y conocimiento). } \\
20 \text { (creatividad). } \\
21 \text { (capacidad para identificar oportunidades). } \\
22 \text { y } 23 \text { (iniciativa). } \\
26 \text { y } 27 \text { (capacidad de cambio). } \\
28 \text { (capacidad para aprender y evolucionar). }\end{array}$ \\
\hline $\begin{array}{l}\text { Categoría } 3 \\
\text { Rasgos de ejecución } \\
\text { del emprendedor social. }\end{array}$ & $\begin{array}{l}3 \text { y } 9 \text { (motivación al logro). } \\
4,5 \text { y } 6 \text { (capacidad para asumir riesgos). } \\
7 \text { y } 8 \text { (confianza). }\end{array}$ \\
\hline
\end{tabular}

\section{Discusión y conclusiones}

Tras revisar la bibliografía referente al emprendimiento y, más concretamente, sobre el emprendimiento social, consideramos que el cuestionario creado tiene la suficiente solidez teórica para ser utilizado como instrumento de medida de este último. Cabe resaltar que su constitución definitiva recoge la totalidad de los rasgos del emprendedor social definidos por Bacq y Janssen (2011), Choi y Majumdar (2014), Weerawardena y Sullivan (2006) y Haugh (2005), lo que demuestra la adecuada amplitud de la herramienta para detectar este tipo de personalidad.

Por otra parte, el exigente filtrado realizado mediante el juicio de expertos nos asegura un cuestionario de gran calidad, relevancia y comprensión, algo que se ve apoyado al comprobar los datos de los Coeficientes de Concordancia de Kendall (W), significativos en todos los casos. Igualmente, pese a la exigencia de los criterios de selección y a la notable eliminación de ítems, únicamente se descartaron 2 de los 19 rasgos característicos iniciales que definen al emprendedor social. Esto pone de manifiesto nuevamente la correcta fundamentación teórica del cuestionario, así como la apropiada selección de los rasgos característicos que definen al emprendedor social, con lo cual se concluye como positiva la validez del constructo.
Del mismo modo, los excelentes resultados obtenidos en la prueba de fiabilidad, destacando un 0,809 en cuanto al Alfa de Cronbach, no hacen más que reforzar la valoración del cuestionario, poniendo de manifiesto su fiabilidad, algo que también podemos ver reflejado en los datos de la prueba piloto realizada.

Finalmente, respecto a la extracción de factores comunes, el análisis estadístico demuestra que los ítems seleccionados se agrupan formando tres grandes dimensiones. Aunque dicha agrupación no coincide completamente con nuestro planteamiento inicial, consideramos que se debe básicamente a cuestiones terminológicas y de interpretación de los rasgos característicos seleccionados, no alterando por ello el valor de su selección.

Por todo ello, consideramos que el cuestionario creado es una herramienta válida para la valoración del emprendimiento social mediante la aplicación de programas de Aprendizaje-Servicio con alumnado universitario en el ámbito de la Educación Física, cumpliendo así con nuestro objetivo inicial. No obstante, considerando los datos obtenidos y la fundamentación teórica del mismo, creemos que también puede ser útil para medir el emprendimiento social en diferentes entornos sociales, con otro tipo de colectivos y mediante otras actuaciones pedagógicas. 


\section{Anexo 1: Cuestionario para juicio de expertos}

El material que a continuación presentamos es una recopilación de ítems de diferentes cuestionarios para valorar el emprendimiento social de los encuestados. Teniendo en cuenta los diferentes aspectos que determinan el concepto de emprendimiento social que hemos desarrollado, este material se dividirá en 3 grandes categorías con sus respectivas secciones:

CATEGORÍA 1- Aspectos de carácter personal (37 ítems): Liderazgo, motivación al logro, capaz de asumir riesgos, confianza, organización, responsabilidad, e integrado en redes sociales con acceso a información y conocimiento (contactos)

CATEGORÍA 2- Aspectos de carácter social (26 ítems): Tolerancia, cooperación/ayuda, coheren$\mathrm{cia} /$ compromiso, conciencia social, y convivencia/respeto bien público.

CATEGORÍA 3- Aspectos de carácter innovador (33 ítems): Creatividad, identificar oportunidades (problemas), iniciativa, capaz de generar ideas, capacidad de cambio, capacidad para aprender y evolucionar, y tolerancia al fracaso.

\section{TOTAL: 96 ítems}

\begin{tabular}{|c|c|}
\hline \multicolumn{2}{|c|}{ TABLA DE CRITERIOS PARA LA VALORACIÓN DE LOS ÍTEMS } \\
\hline 1. CALIDAD DEL ÍTEM & $\begin{array}{l}\text { La formulación del ítem está: ¿Libre de material irrelevante?: } \\
\text { 1. Mucha } \\
\text { 2. Regular } \\
\text { 3. Poca }\end{array}$ \\
\hline 2. RELEVANCIA & $\begin{array}{l}\text { ¿El ítem mide un aspecto relevante sobre el concepto de emprendimiento social? } \\
\text { 1. Muy relevante } \\
\text { 2. Relevante } \\
\text { 3. Nada relevante }\end{array}$ \\
\hline 3. COMPRENSIÓN & $\begin{array}{l}\text { 1. De fácil comprensión } \\
\text { 2. De comprensión media } \\
\text { 3. De difícil comprensión }\end{array}$ \\
\hline $\begin{array}{l}\text { 4. DIMENSIÓN ASO- } \\
\text { CIADA }\end{array}$ & $\begin{array}{l}\text { Debe indicar el número de la sección a la que considera que hace referencia el ítem: } \\
\text { CATEGORÍA 1. Aspectos de carácter personal ( } 37 \text { ítems): } \\
\text { 1. Liderazgo } \\
\text { 2. Motivación al logro } \\
\text { 3. Capaz de asumir riesgos } \\
\text { 4. Confianza } \\
\text { 5. Organización } \\
\text { 6. Responsabilidad } \\
\text { 7. Integrado en redes sociales con acceso a información y conocimiento (contactos) } \\
\text { CATEGORÍA 2. Aspectos de carácter social (26 ítems): } \\
\text { 1. Tolerancia } \\
\text { 2. Cooperación/ayuda } \\
\text { 3. Coherencia/compromiso } \\
\text { 4. Conciencia social } \\
\text { 5. Convivencia/Respeto bien público } \\
\text { CATEGORÍA 3. Aspectos de carácter innovador ( } 33 \text { ítems): } \\
\text { 1. Creatividad } \\
\text { 2. Identificar oportunidades (problemas) } \\
\text { 3. Iniciativa } \\
\text { 4. Capaz de generar ideas } \\
\text { 5. Capacidad de cambio } \\
\text { 6. Capacidad para aprender y evolucionar } \\
\text { 7. Tolerancia al fracaso }\end{array}$ \\
\hline
\end{tabular}




\section{TABLA DE ANÁLISIS DE ÍTEMS}

Indique en la casilla del criterio el número que considera que representa mejor su valoración. Debajo existe un apartado de observaciones en el que puede sugerir otras formas de reescribir el ítem.

\begin{tabular}{|c|c|c|c|c|c|}
\hline \multicolumn{6}{|c|}{ CATEGORÍA 1- Aspectos de carácter personal (37 ítems) } \\
\hline & & $\begin{array}{l}\text { Calidad } \\
\text { del ítem }\end{array}$ & Relevancia & Comprensión & $\begin{array}{c}\text { Dimensión } \\
\text { asociada }\end{array}$ \\
\hline 1 & Me gusta tomar la iniciativa y que los/as demás sigan mis pasos. & & & & \\
\hline 2 & Mi capacidad de influir sobre los/as demás es baja. & & & & \\
\hline 3 & Me gusta trabajar con un equipo de personas a las que coordinar. & & & & \\
\hline 4 & $\begin{array}{l}\text { Cuando se trabaja en grupo, prefiero ser el/la líder en lugar de un/a } \\
\text { seguidor/a. }\end{array}$ & & & & \\
\hline 5 & Suelo tomar el control en situaciones complicadas. & & & & \\
\hline 6 & Soy una persona decidida y determinada para lograr mis objetivos. & & & & \\
\hline 7 & $\begin{array}{l}\text { Cuando hago planes, estoy seguro/a de que puedo lograr que } \\
\text { funcionen. }\end{array}$ & & & & \\
\hline 8 & Siempre he trabajado duro para estar entre los/as mejores. & & & & \\
\hline 9 & $\begin{array}{l}\text { Me siento bien cuando soy el/la responsable del éxito de mi pro- } \\
\text { pios proyectos. }\end{array}$ & & & & \\
\hline 10 & Me siento bien aunque la calidad de mi trabajo sea baja. & & & & \\
\hline 11 & $\begin{array}{l}\text { Cuando me planteo los objetivos no me preocupan el tiempo ni } \\
\text { los recursos invertidos. }\end{array}$ & & & & \\
\hline 12 & Pienso que es necesario arriesgarme para progresar. & & & & \\
\hline 13 & $\begin{array}{l}\text { Creo que las personas que se arriesgan tienen más probabilida- } \\
\text { des de tener éxito que las que no lo hacen. }\end{array}$ & & & & \\
\hline 14 & $\begin{array}{l}\text { Me gusta apostar por una buena idea aunque no sea del todo se- } \\
\text { gura. }\end{array}$ & & & & \\
\hline 15 & Me gusta tomar riesgos calculados con las nuevas ideas. & & & & \\
\hline 16 & Me veo capacitado/a para enfrentarme a cualquier situación. & & & & \\
\hline 17 & Creo en mis posibilidades. & & & & \\
\hline 18 & Soy reticente a solicitar ayuda. & & & & \\
\hline 19 & $\begin{array}{l}\text { Me considero autosuficiente para poder conseguir lo que me pro- } \\
\text { pongo. }\end{array}$ & & & & \\
\hline 20 & Me cuesta decidirme porque no me siento preparado/a. & & & & \\
\hline 21 & Cuándo inicio una tarea me fijo metas y objetivos claros. & & & & \\
\hline 22 & $\begin{array}{l}\text { Utilizo mis recursos de la forma más correcta posible para alcan- } \\
\text { zar los objetivos. }\end{array}$ & & & & \\
\hline 23 & $\begin{array}{l}\text { Me es difícil planificar mis recursos materiales y personales para ob- } \\
\text { tener resultados. }\end{array}$ & & & & \\
\hline 24 & Me pongo metas a mí mismo/a para dirigir mis actividades. & & & & \\
\hline
\end{tabular}




\begin{tabular}{|c|c|c|c|c|}
\hline 25 & $\begin{array}{l}\text { Para tener éxito creo que es importante utilizar el tiempo adecua- } \\
\text { damente }\end{array}$ & & & \\
\hline 26 & Puedo trabajar hasta tarde para alcanzar una meta. & & & \\
\hline 27 & $\begin{array}{l}\text { Cumplo con aquello que me he propuesto a mí mismo/a o a los } \\
\text { demás. }\end{array}$ & & & \\
\hline 28 & Normalmente hago las cosas como me dicen. & & & \\
\hline 29 & Asumo las consecuencias de lo que he dicho o hecho. & & & \\
\hline 30 & Hago cada trabajo tan a fondo como sea posible. & & & \\
\hline 31 & $\begin{array}{l}\text { Me siento mejor en mi trabajo cuando sé que he seguido los pro- } \\
\text { cedimientos correctos. }\end{array}$ & & & \\
\hline 32 & Suelo recurrir al consejo de personas mayores y experimentadas. & & & \\
\hline 33 & Prefiero trabajar con más personas. & & & \\
\hline 34 & Tengo relaciones sociales que me permitirían iniciar proyectos. & & & \\
\hline 35 & $\begin{array}{l}\text { Creo que para tener éxito es importante llevarse bien con las per- } \\
\text { sonas con las que nos relacionamos. }\end{array}$ & & & \\
\hline 36 & Suelo investigar e informarme sobre las cosas que me interesan. & & & \\
\hline 37 & $\begin{array}{l}\text { Tengo acceso a información de apoyo para comenzar a empren- } \\
\text { der proyectos }\end{array}$ & & & \\
\hline
\end{tabular}

\begin{tabular}{|c|c|c|c|c|c|}
\hline \multicolumn{6}{|c|}{ CATEGORÍA 2- Aspectos de carácter social (26 ítems) } \\
\hline & & $\begin{array}{l}\text { Calidad } \\
\text { del ítem }\end{array}$ & Relevancia & Comprensión & $\begin{array}{c}\text { Dimensión } \\
\text { asociada }\end{array}$ \\
\hline 38 & $\begin{array}{l}\text { No me importa trabajar con personas de diferentes religio- } \\
\text { nes. }\end{array}$ & & & & \\
\hline 39 & Me gusta relacionarme con personas de diferentes razas. & & & & \\
\hline 40 & No me importaría convivir con un anciano. & & & & \\
\hline 41 & $\begin{array}{l}\text { Solo converso con los/as compañeros/as de clase que me } \\
\text { caen mal. }\end{array}$ & & & & \\
\hline 42 & Me encantaría colaborar gratuitamente en una O.N.G. & & & & \\
\hline 43 & $\begin{array}{l}\text { Estoy de acuerdo en el pago de impuestos para financiar } \\
\text { los servicios públicos. }\end{array}$ & & & & \\
\hline 44 & $\begin{array}{l}\text { Pienso que cuanto más dinero gana una persona más debe } \\
\text { compartir con los demás. }\end{array}$ & & & & \\
\hline 45 & Me gusta ayudar a mis amigos/as de clase. & & & & \\
\hline 46 & $\begin{array}{l}\text { Las personas que ayudan a los demás son un ejemplo que } \\
\text { debo seguir. }\end{array}$ & & & & \\
\hline 47 & $\begin{array}{l}\text { No me importa dedicar tiempo a ayudar a los más desfavo- } \\
\text { recidos. }\end{array}$ & & & & \\
\hline 48 & $\begin{array}{l}\text { Estoy dispuesto/a a dedicar dos horas a la semana para dar } \\
\text { clase de apoyo a niños/as que lo necesiten. }\end{array}$ & & & & \\
\hline 49 & $\begin{array}{l}\text { Acompañaría al cuarto de baño a un/a compañero/a de clase } \\
\text { discapacitado. }\end{array}$ & & & & \\
\hline
\end{tabular}




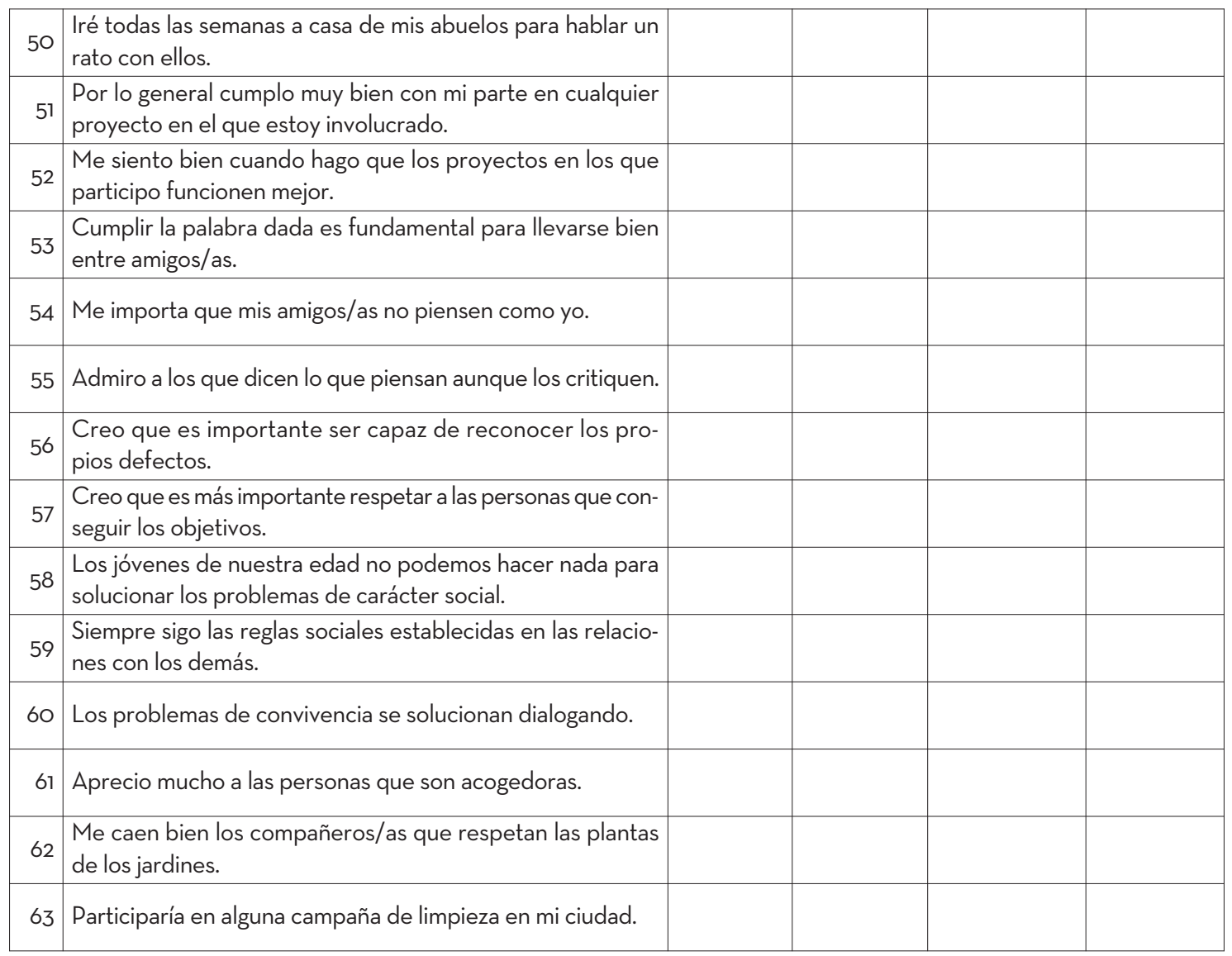

\begin{tabular}{|c|c|c|c|c|c|}
\hline \multicolumn{6}{|c|}{ CATEGORÍA 3- Aspectos de carácter innovador (33 ítems) } \\
\hline & & $\begin{array}{l}\text { Calidad } \\
\text { del ítem }\end{array}$ & Relevancia & Comprensión & $\begin{array}{c}\text { Dimensión } \\
\text { asociada }\end{array}$ \\
\hline 64 & $\begin{array}{l}\text { Consigo hacer las cosas de manera imaginativa y diferente } \\
\text { a como lo hacen otras personas. }\end{array}$ & & & & \\
\hline 65 & $\begin{array}{l}\text { Me resulta difícil encontrar múltiples soluciones a un mismo } \\
\text { problema. }\end{array}$ & & & & \\
\hline 66 & $\begin{array}{l}\text { Me emociona crear mis propias oportunidades de crecimiento } \\
\text { personal. }\end{array}$ & & & & \\
\hline 67 & $\begin{array}{l}\text { Creo que es importante buscar continuamente nuevas ma- } \\
\text { neras de hacer las cosas. }\end{array}$ & & & & \\
\hline 68 & Veo nuevas utilidades en objetos comunes. & & & & \\
\hline 69 & Estoy tranquilo/a cuando me enfrento a dificultades. & & & & \\
\hline 70 & Puedo crear oportunidades y aprovecharlas. & & & & \\
\hline 71 & $\begin{array}{l}\text { A menudo sacrifico mi comodidad personal con el fin de apro- } \\
\text { vechar las oportunidades. }\end{array}$ & & & & \\
\hline 72 & $\begin{array}{l}\text { Mi habilidad para tratar con la gente me ha permitido crear } \\
\text { muchas de mis oportunidades. }\end{array}$ & & & & \\
\hline 73 & $\begin{array}{l}\text { He intervenido alguna vez en la puesta en marcha de pro- } \\
\text { yectos tales como asociaciones. }\end{array}$ & & & & \\
\hline 74 & $\begin{array}{l}\text { He participado o participo en alguna actividad de carácter } \\
\text { grupal. }\end{array}$ & & & & \\
\hline 75 & $\begin{array}{l}\text { Me es difícil llevar a la práctica los propósitos que me plan- } \\
\text { teo a lo largo del año. }\end{array}$ & & & & \\
\hline
\end{tabular}




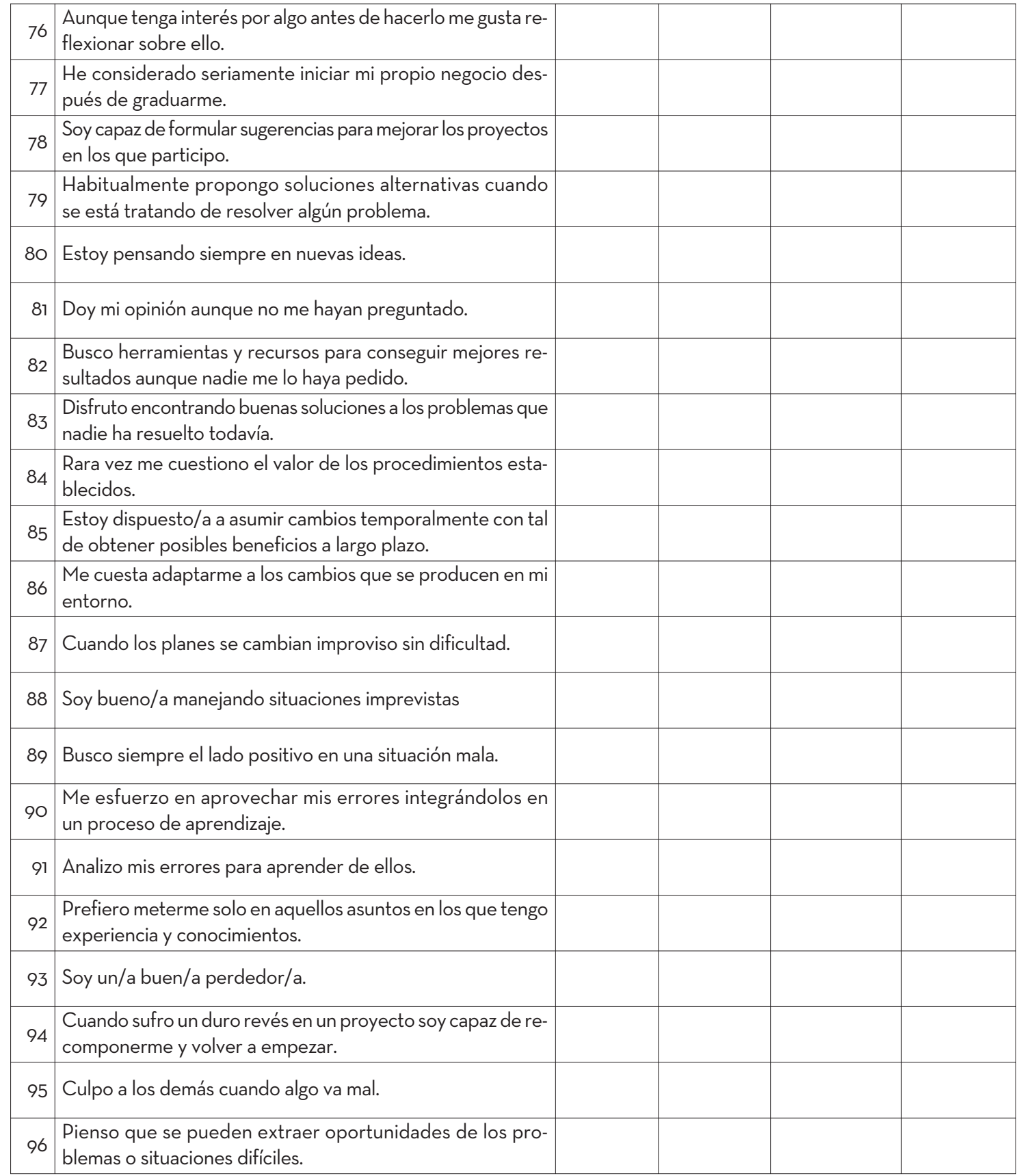

\section{OBSERVACIONES}




\section{Anexo 2: Cuestionario para medir el emprendimiento social desarrollado mediante programas de Aprendizaje-Servicio en Educación Física}

\begin{tabular}{|c|c|c|c|c|c|c|}
\hline & & $\begin{array}{c}\text { Muy en } \\
\text { desacuerdo }\end{array}$ & $\begin{array}{c}\text { En } \\
\text { desacuerdo }\end{array}$ & Indeciso & $\begin{array}{c}\mathrm{De} \\
\text { acuerdo }\end{array}$ & $\begin{array}{l}\text { Muy de } \\
\text { acuerdo }\end{array}$ \\
\hline 1 & $\begin{array}{l}\text { Me gusta trabajar con un equipo de personas a las que } \\
\text { coordinar. }\end{array}$ & 1 & 2 & 3 & 4 & 5 \\
\hline 2 & Cuando se trabaja en grupo, prefiero ser el/la líder. & 1 & 2 & 3 & 4 & 5 \\
\hline 3 & Soy una persona decidida a lograr mis objetivos. & 1 & 2 & 3 & 4 & 5 \\
\hline 4 & Pienso que es necesario arriesgarme para progresar. & 1 & 2 & 3 & 4 & 5 \\
\hline 5 & $\begin{array}{l}\text { Creo que las personas que se arriesgan tienen más pro- } \\
\text { babilidades de tener éxito que las que no lo hacen. }\end{array}$ & 1 & 2 & 3 & 4 & 5 \\
\hline 6 & Me gusta tomar riesgos calculados con las nuevas ideas. & 1 & 2 & 3 & 4 & 5 \\
\hline 7 & $\begin{array}{l}\text { Me veo capacitado/a para enfrentarme a la mayoría de } \\
\text { situaciones. }\end{array}$ & 1 & 2 & 3 & 4 & 5 \\
\hline 8 & Creo en mis posibilidades. & 1 & 2 & 3 & 4 & 5 \\
\hline 9 & $\begin{array}{l}\text { Me considero autosuficiente para poder conseguir lo } \\
\text { que me propongo. }\end{array}$ & 1 & 2 & 3 & 4 & 5 \\
\hline 10 & Asumo las consecuencias de lo que he dicho o hecho. & 1 & 2 & 3 & 4 & 5 \\
\hline 11 & Hago cada trabajo tan a fondo como sea posible. & 1 & 2 & 3 & 4 & 5 \\
\hline 12 & Prefiero trabajar con más personas. & 1 & 2 & 3 & 4 & 5 \\
\hline 13 & $\begin{array}{l}\text { Tengo acceso a información de apoyo para comenzar } \\
\text { a emprender proyectos. }\end{array}$ & 1 & 2 & 3 & 4 & 5 \\
\hline 14 & Me encantaría colaborar gratuitamente en una O.N.G. & 1 & 2 & 3 & 4 & 5 \\
\hline 15 & Me gusta ayudar a mis amigos de clase/trabajo. & 1 & 2 & 3 & 4 & 5 \\
\hline 16 & $\begin{array}{l}\text { Las personas que ayudan a los demás son un ejemplo } \\
\text { a seguir. }\end{array}$ & 1 & 2 & 3 & 4 & 5 \\
\hline 17 & $\begin{array}{l}\text { Por lo general cumplo muy bien con mi parte en cual- } \\
\text { quier proyecto en el que estoy involucrado/a. }\end{array}$ & 1 & 2 & 3 & 4 & 5 \\
\hline 18 & Los problemas de convivencia se solucionan dialogando. & 1 & 2 & 3 & 4 & 5 \\
\hline 19 & $\begin{array}{l}\text { Consigo hacer las cosas de manera imaginativa y dife- } \\
\text { rente a como lo hacen otras personas. }\end{array}$ & 1 & 2 & 3 & 4 & 5 \\
\hline 20 & Veo nuevas utilidades en objetos comunes. & 1 & 2 & 3 & 4 & 5 \\
\hline 21 & Puedo crear oportunidades y aprovecharlas. & 1 & 2 & 3 & 4 & 5 \\
\hline 22 & $\begin{array}{l}\text { He intervenido alguna vez en la puesta en marcha de } \\
\text { proyectos de grupo o asociaciones. }\end{array}$ & 1 & 2 & 3 & 4 & 5 \\
\hline 23 & $\begin{array}{l}\text { He considerado seriamente iniciar mi propio negocio } \\
\text { después de graduarme. }\end{array}$ & 1 & 2 & 3 & 4 & 5 \\
\hline 24 & $\begin{array}{l}\text { Soy capaz de formular sugerencias para mejorar los pro- } \\
\text { yectos en los que participo. }\end{array}$ & 1 & 2 & 3 & 4 & 5 \\
\hline 25 & $\begin{array}{l}\text { Disfruto encontrando buenas soluciones a los proble- } \\
\text { mas que nadie ha resuelto todavía. }\end{array}$ & 1 & 2 & 3 & 4 & 5 \\
\hline
\end{tabular}




\begin{tabular}{|c|c|c|c|c|c|c|}
\hline 26 & $\begin{array}{l}\text { Cuando los planes se cambian improviso } \\
\text { sin dificultad. }\end{array}$ & 1 & 2 & 3 & 4 & 5 \\
\hline 27 & Soy bueno/a manejando situaciones imprevistas & 1 & 2 & 3 & 4 & 5 \\
\hline 28 & Busco siempre el lado positivo en una situación mala. & 1 & 2 & 3 & 4 & 5 \\
\hline 29 & Analizo mis errores para aprender de ellos. & 1 & 2 & 3 & 4 & 5 \\
\hline 30 & $\begin{array}{l}\text { Pienso que se pueden extraer oportunidades de los } \\
\text { problemas o situaciones difíciles. }\end{array}$ & 1 & 2 & 3 & 4 & 5 \\
\hline
\end{tabular}

\section{Referencias bibliográficas}

Akhtar, A., Keith, J., \& Riaz, H. (2009). Entrepreneurial inclinations of prospective teachers. New Horizons in Education, $56(2), 1-16$

Aliaga, C., \& Schalk, A. (2010). E²: empleabilidad temprana y emprendimiento. Dos grandes desafíos en la formación superior en Chile. Calidad en la Educación, (33), 319-337.

Alonso, F. J. (2004). Adquisición de actitudes de responsabilidad social a través de un programa de voluntariado. Doctoral thesis. Valencia: Universidad de Valencia.

Alvord, S. H., Brown, L. D., \& Letts, C. W. (2004). Social Entrepreneurship and Societal Transformation: An Exploratory Study. The Journal of Applied Behavioral Science, 4O(3), 260-282. doi: 10.1177/0021886304266847

Auerswald, P. (2009). Creating Social Value. Stanford Social Innovation Review, 7(2), 51-55.

Bacq, S., \& Janssen, F. (2011). The multiple faces of social entrepreneurship: A review of definitional issues based on geographical and thematic criteria. Entrepreneurship \& Regional Development: An International Journal, 23(5-6), 373-403. doi:10.1080/08985626.2011.577242

Centros Europeos de Empresas Innovadoras CEEl. (2012).. Test del perfil emprendedor. Retrieved from http://ceeivalencia.emprenemjunts.es/index.php?op=65\&tFM=70

Chell, E., Haworth, J. M., \& Brearley, S. A. (1991). The entrepreneurial personality: concepts, cases and categories. London: Routledge.

Choi, N., \& Majumdar, S. (2014). Social entrepreneurship as an essentially contested concept: Opening a new avenue for systematic future research. Journal of Business Venturing, 29(3), 363-376. doi:10.1016/j.jbusvent.2013.05.001

Cieza, J. A. (2010). El compromiso y la participación comunitaria de los centros escolares. Un nuevo espacio-tiempo de intervención socioeducativa. Pedagogía Social. Revista Interuniversitaria, 17, 123-136. doi: 10.7179/psri

Collins, C. J., Hanges, P. J., \& Locke, E. A. (2004). The relationship of achievement motivation to entrepreneurial behaviour: a meta-analysis. Human Performance, 17(1), 95-117.

De la Vega, I., Corduras, A., Cruz, C., Justo, R., \& González, I. (2006). Global Entrepreneurship Monitor. Informe Ejecutivo GEM España. Madrid: Instituto de Empresa.

De Pablo, l., Santos, B., \& Bueno, Y. (2004): Las dimensiones del perfil del emprendedor: contraste empírico con emprendedores de éxito. In S. Roig, D. Ribeiro, V. R. Torcal, A. De la Torre, \& E. Cerver, (Eds.), El emprendedor innovador y la creación de empresas de l+D+l (pp. 813-830). Valencia: Universidad de Valencia.

Enciso, J. D. (2010). El emprendimiento y el bien común: ¿competencias complementarias o excluyentes? Educación y Educadores, 13(1), 63-76.

Escobar-Pérez, J., \& Cuervo-Martínez, A. (2008). Validez de contenido y juicio de expertos: una aproximación a su utilización. Avances en medición, 6, 27-36.

Gil, J. (2012). El Aprendizaje-Servicio en la enseñanza superior: una aplicación en el ámbito de la Educación Física. Doctoral thesis. Castellón: Universitat Jaume I.

González, J., Sánchez, P., \& Jornet, J. M. (2011). Estudio de validación por jueces de una escala para medir la competencia de compromiso en universitarios. Paper presented at XV Congreso Nacional y I Internacional de Modelos de Investigación Educativa: Investigación y Educación en un mundo en red, Madrid.

González, R., \& Zúñiga, A. (2011). Método CEPCES para la evaluación del potencial emprendedor. Journal of Technology Management \& Innovation, 6, 77-99.

Haugh, H. (2005). A research agenda for social entrepreneurship. Social Enterprise Journal, 1(1), 1-12.

Hoogendoorn, B., Pennings, E., \& Thurik, R. (2010). What Do We Know About Social Entrepreneurship: An Analysis of Empirical Research. (ERIM Report Series Research in Management ERS-2009-044-ORG). Rotterdam: Erasmus Research Institute of Management. Retrieved from http://hdl.handle.net/1765/16558 
Huefner, J., Hunt H. K., \& Robinson P.B. (1996). A comparison of four scales predicting entrepreneurship. Academy of Entrepreneurship Journal, $7(2), 56-80$.

Kafati, K. (2012). Cuestionario para medir la capacidad emprendedora. Instituto Nacional de Formación Profesional. Retrieved from http://www.infomipyme.com/Docs/HN/Offline/Hn_ch_05.htm

Langstraat, L. \& Bowdon, M. (2O11). Service-learning and critical emotion studies: on the perils of empathy and the politics of compassion. Michigan Journal of Community Service Learning, spring, 5-14.

Lanzas, A., Lanzas, V., \& Castaño, J. C. (2006). Modelo Administrativo para una unidad de emprendimiento en instituciones públicas de educación superior, caso Universidad Tecnológica de Pereira. Scientia Et Technica, (30), 239-249.

Manes, N., Hatt, B. \& Wideman, R. (2013). Service learning as a practicum experience in pre-service education program. Canadian journal of higher education revue canadienne d'enseignement supérieur, 43(1), 80-99.

Massetti, B. L. (2008). The social entrepreneurship matrix as a "tipping point" for economic change. St. John's University, 10(3), 1-8.

Ministerio de Industria, Comercio y Turismo, y Ministerio de Educación y Ciencia. (2003). El espíritu emprendedor. Motor de futuro. Guía del profesor, Madrid: Secretaría General de Educación y Formación Profesional.

Moraleda, M., González, A., \& García-Gallo, J. (2004). AECS: actitudes y estrategias cognitivas sociales (2a ed.). Madrid: TEA.

Orrego, C. (2009). La fenomenología y el Emprendimiento. Pensamiento y gestión, Universidad del Norte, (27), 235-252

Palacios, G. (2010). Emprendimiento social: integrando a los excluidos en el ámbito rural. Revista de Ciencias Sociales (RCS), 16(4), 579-590

Rauch, A., \& Frese, M. (2000). Psychological approaches to entrepreneurial success: a general model and an overview of findings. In C. L. Cooper, y I. T. Robertson (Eds.), International review of industrial and organizational psychology (pp. 101-141). Chischester: Wiley.

Rauch, A., \& Frese, M. (2007). Let's put the person back into entrepreneurship research: a metaanalysis on the relationship between business owners' personality traits, business creation, and success. European Journal of Work and Organizational Psychology, 16(4), 353-385.

Real Academia Española. (2012). Emprender. In Diccionario de la lengua española (22a ed.), Retrieved from http://lema.rae.es/drae/?val=emprender

Roberts, D., \& Woods, C. (2005). Changing the world on a shoestring: the concept of social entrepreneurship. University of Auckland Business Review, 7(1), 45-51.

Short, J. C., Moss, T. W., \& Lumpkin, G. T. (2009). Research in social entrepreneurship: past contributions and future opportunities. Strategic entrepreneurship journal, 3(2), 161-194. doi:10.1002/sej.69

Spear, R. (2006). Social entrepreneurship: a different model. International Journal of Social Economics, 33 (5/6), 399-410. doi:10.1108/03068290610660670

Stewart, W. H., \& Roth, P. L. (2001). Risk propensity differences between entrepreneurs and managers: a meta-analytic review. Journal of Applied Psychology, 86(1), 145-153. doi: 10.1037/0021-9010.86.1.145

Stewart, W. H., \& Roth, P. L. (2004). Data-quality affects meta-analytic conclusions: a response to Miner and Raju (2004) concerning entrepreneurial risk propensity. Journal of Applied Psychology, 89(1), 14-21. doi: 10.1037/0021-9010.89.1.14

Summers, B., Williamson, T., \& Read, D. (2004). Does method of acquisition affect the quality of expert judgment? A comparison of education with on-the-job learning. Journal of Occupational and Organizational Psychology. 77(2), 237-258.

Valls, N., Villa, A., Martínez, S., \& Hernando A. (2009). Emprendimiento social juvenil. 18 Buenas prácticas. Barcelona: Fundación Bertelsmann.

Weerawardena, J., \& Sullivan Mort, G. (2006). Investigating social entrepreneurship: A multidimensional model. Journal of World Business, 41(1), 21-35. doi:10.1016/j.jwb.2005.09.001

Zahra, S. A., Filatotchev, I., \& Wright, M. (2009). How do threshold firms sustain corporate entrepreneurship? The role of boards and absorptive capacity. Journal of Business Venturing, 24(3), 248-260.

Zhao, H., \& Seibert, S. E. (2006). The big five personality dimensions and entrepreneurial status: a meta-analytical review. Journal of Applied Psychology, 91 (2), 259-271.

\section{Notas}

${ }^{1}$ Ley Orgánica 2/2006, de 3 de mayo, de Educación; y Ley Orgánica 8/2013, de 9 de diciembre, para la mejora de la calidad educativa. 


\section{CÓMO CITAR ESTE ARTÍ́CULO}

Capella, C., Gil, J., Martí, M., \& Ruiz-Bernardo, P. (2016). Construcción de un cuestionario para medir el emprendimiento social en educación física. Pedagogía Social. Revista Interuniversitaria, 28 169-188. DOI:10.7179/PSRI_2016.28.13

\section{DIRECCIÓN DE LOS AUTORES}

Carlos Capella Peris. Departament d’Educació Av. Vicent Sos Baynat, s/n 12071 Castelló de la Plana. Dirección de correo/e-mail: capellac@uji.es

Jesús Gil Gómez. Departament d’Educació Av. Vicent Sos Baynat, s/n 12071 Castelló de la Plana. Dirección de correo/e-mail: jegil@uji.es

Manuel Martí Puig. Departament d’Educació Av. Vicent Sos Baynat, s/n 12071 Castelló de la Plana. Dirección de correo/e-mail: puig@uji.es

Paola Ruiz-Bernardo. Departament d'Educació Av. Vicent Sos Baynat, s/n 12071 Castelló de la Plana. Dirección de correo/e-mail: ruizma@uji.es

\section{PERFIL ACADÉMICO}

Carlos Capella Peris. Departamento de Educación de la Universidad Jaume I de Castellón. Licenciado en Ciencias de la Educación Física y el Deporte. Máster en Educación Secundaria y Doctorando en Educación Secundaria. Profesor del área de Expresión Corporal. Estudia los efectos de la aplicación del Aprendizaje-Servicio y defiende su promoción en el ámbito de la Educación Física. Autor de varios artículos, comunicaciones y ponencias en congresos y jornadas de investigación sobre dicha temática.

Jesús Gil Gómez. Departamento de Educación de la Universidad Jaume I de Castellón. Doctor en Educación. Licenciado en Educación Física. Funcionario del cuerpo de Profesores de Educación Secundaria. Profesor del área de Expresión Corporal. Sus líneas de investigación están centradas en la innovación metodológica. Se ha especializado en el Aprendizaje-Servicio. Ha publicado libros, capítulos de libros y artículos relacionados con estas temáticas, además de dirigir y participar en congresos nacionales e internacionales.

Manuel Martí Puig. Departamento de Educación de la Universidad Jaume I de Castellón. Doctor en Educación por la Universidad de Valencia. Profesor del área de Teoría e Historia de la Educación. Sus líneas de investigación están centradas en el aprendizaje cooperativo y en la investigación narrativa (historias de vida). Ha publicado libros, capítulos de libros y artículos relacionados con estas temáticas, además de dirigir y participar en congresos nacionales e internacionales.

Paola Ruiz-Bernardo. Departamento de Educación de la Universidad Jaume I de Castellón. Doctora en Educación por la Universidad Jaume I. Licenciada en Pedagogía. Profesora del área de Didáctica y Organización Escolar. Sus líneas de investigación están centradas en la innovación metodológica y el desarrollo de competencias interculturales. Ha publicado libros, capítulos de libros y artículos relacionados con estas temáticas. Ha impartido cursos de formación para el profesorado. 